CONFLICTO POLÍTICO, SALUBRIDAD PÚBLICA Y ADMINISTRACIÓN URBANA EN EL DISTRITO FEDERAL: VIEJAS SOLUCIONES A VIEJOS PROBLEMAS, 1920-1924 Sergio Miranda Pacheco*

RESUMEN: El texto analiza las medidas políticoadministrativas mediante las cuales el gobierno federal, por medio del Poder Ejecutivo, buscó resolver los graves problemas de salubridad pública que afectaban a las poblaciones del Distrito Federal durante el gobierno de Álvaro Obregón, y muestra la limitación de dichas medidas impuesta por el carácter centralista del gobierno mexicano de aquellos años.

Palabras Clave: Distrito Federal, Ciudad de México, ayuntamientos, salud pública, administración urbana, Álvaro Obregón.
ABSTRACT: This article examines the political and administrative measures undertaken by the federal government in an attempt to solve the serious public health problems in Distrito Federal during Alvaro Obregon's term. It further demonstrates the limitations of those measures, resulting from the centralism that characterized Mexican government during that time.

KEYWORDS: Distrito Federal, Mexico City, municipalities, public health, urban administration, Álvaro Obregón. 


\section{CONFLICTO POLÍTICO, SALUBRIDAD PÚBLICA Y ADMINISTRACIÓN URBANA EN EL DISTRITO FEDERAL: VIEJAS SOLUCIONES A VIEJOS PROBLEMAS, 1920-1924}

Los primeros gobiernos de México surgidos de la Revolución enfrentaron la necesidad de resolver una grave problemática urbana en la capital del país, definida fundamentalmente por la insuficiencia de los servicios públicos, la creciente demanda de los mismos por parte de una población en constante crecimiento, y una estructura urbana con profundas desigualdades sociales. El régimen porfirista había empezado a atender esta problemática apenas siete años antes de ser derrocado, mediante la concentración en manos del poder ejecutivo de los recursos y facultades de gobierno de las corporaciones municipales del Distrito Federal, con lo cual los constantes conflictos entre autoridades locales y federales queda- ron atrás y se emprendió una reforma administrativa que tenía como propósito general resolver los problemas más acuciantes de la ciudad de México y de las otras municipalidades del Distrito.

Si bien el régimen porfirista estuvo lejos de haber solucionado la problemática urbana de las distintas poblaciones del Distrito, el diagnóstico de la misma y las medidas emprendidas para su atención quedaron truncadas con el triunfo de las fuerzas revolucionarias. Tras el triunfo de éstas, México entró a un nuevo régimen político, dentro del cual el municipio libre fue uno de los pilares sobre los cuales se apostó la construcción de un nuevo Estado. Al reinstalarse la autonomía municipal en el Distrito Fede- 
ral, el activismo y contienda por el poder de las nuevas fuerzas políticas instaladas en los ayuntamientos resucitaron las dificultades y conflictos entre autoridades locales y federales por la falta de una debida organización de las funciones y definición legal de las facultades, correspondientes a ambas esferas de gobierno, y ello no dejó de repercutir en el funcionamiento de los servicios públicos, sobre todo los referidos a la higiene y salubridad públicas.

En particular, bajo el gobierno de Álvaro Obregón los habitantes del Distrito Federal padecieron los efectos de varias crisis de los servicios urbanos: la disminución del flujo de energía eléctrica en 1921, que obligó a suspender la calefacción y los anuncios luminosos, y modificó los horarios de comercio; la escasez de agua en 1922, en la que estuvieron involucrados los opositores al gobierno y que dio lugar a que éstos ganaran las elecciones municipales de 1923 en la ciudad de México; la crónica escasez de vivienda de alquiler para los sectores populares, que propició la especulación con el suelo y la vivienda y el descontento social manifiesto en el movimiento inquilinario de 1922; $\mathrm{y}$, finalmente, la insalubridad pública, producida por la falta de servicios urbanos mínimos en las numerosas colonias que se fundaron en la periferia de la ciudad de México, sin apego a los reglamentos, en abierto contraste con aquellas colonias situadas céntricamente que disfrutaban de todos los servicios y los modernos fraccionamientos como el de Chapultepec Heights. ${ }^{1}$

En efecto, las precarias condiciones de los asentamientos urbanos populares (calles, mercados, plazas, parques, casas, etc.) se mantuvieron como uno de los principales problemas para los habitantes del Distrito. Viviendas de colonias como la Morelos no contaban con ningún servicio sanitario, por lo que la norma de sus habitantes era defecar al aire libre y en espacios públicos; el agua potable de que disponían era escasa, sus calles carecían de drenaje y ello ocasionaba encharcamientos propicios para la acumulación de basura y enfermedades infecciosas. Junto con esto, por todos los rumbos del Distrito proliferaban los basureros y excusados en los terrenos sin urbanizar; la mayor parte de las colonias populares tenían sin pavimentar sus calles, aumentando el riesgo de enfermedades respiratorias; el agua potable era un bien

${ }^{1}$ Sobre el tema de los problemas sociales, financieros, urbanos y políticos durante el gobierno de Álvaro Obregón, véase Sergio Miranda Pacheco, Historia de la desaparición del municipio en el Distrito Federal, 1998, México, SONER/FP/Uníos; Jorge H. Jiménez Muñoz, La traza del poder. Historia de la politica y los negocios urbanos en el Distrito Federal. De sus orígenes a la desaparición del ayuntamiento (1824-1928), 1993, México, Codex, pp. $180-186$. 
NOTAS

escaso, la población defecaba ya fuera en la coladeras o en la vía pública, los baches generaban basura y encharcamientos. En algunos casos, como en la colonia Peralvillo, no se contaba con banquetas y pavimentos por lo que, durante el tiempo de lluvias, las inundaciones provocaban severos problemas de salud.

El gobierno de Álvaro Obregón emprendió algunas medidas para solucionar la problemática urbana del Distrito, entre ellas el impulso a la construcción de viviendas para satisfacer la demanda de sectores populares y la reorganización del aparato administrativo de los servicios públicos de salubridad, ${ }^{2}$ no sin dejar de atender la conflictividad política alojada en los ayuntamientos que afectaba el cumplimiento de sus funciones públicas, aunque para esto último recurrió también al recurso de afirmar su autoridad mediante la sustitución de ayuntamientos electos por concejos municipales designados por el Ejecutivo, como ocurrió en los municipios de Xochimilco, Tacuba y México. $^{3}$

${ }^{2}$ Para una noticia de los diversos medios que empleó el gobierno de Obregón para impulsar la construcción de vivienda para las clases populares, vid. María Soledad Cruz Rodríguez, Crecimiento urbano y procesos sociales en el Distrito Federal (1920-1928), 1994, México, UAM-Azcapotzalco, pp. 122-132.

${ }^{3}$ Sobre los conflictos electorales en los ayuntamientos del D.F. durante el gobierno de Obregón, vid. Sergio Miranda Pacheco, Historia de la desaparición... op. cit., pp. 150-154.
Frente a esta problemática y apercibido de "la ingente necesidad de proveer a las exigencias de los diferentes ramos de la higiene para satisfacer la salubridad pública del Distrito Federal", el presidente Obregón expidió el 5 de junio de 1922 el acuerdo por el cual se creaba la Comisión Ejecutiva Sanitaria del Distrito Federal dependiente de la Presidencia de la República. ${ }^{4}$ Con esta medida, tendiente a resolver el problema de la salubridad en el Distrito, Obregón actuó como lo hiciera en su momento Porfirio Díaz, es decir, centralizando y colocando en manos del poder ejecutivo la solución a los problemas del Distrito Federal. En otras palabras, nuevamente, pero ahora bajo un gobierno que surgió de una lucha que defendió, entre otras, la bandera de la autonomía municipal, se ensayaban viejas soluciones centralizadoras a los viejos problemas de los servicios urbanos en el Distrito Federal.

La nueva instancia ejecutiva de gobierno quedó integrada por miembros de las distintas dependencias encargadas de atender la salubridad pública, es decir, se formó con un comisionado de cada una de las secretarías de Gobernación, Agricultura y Fomento, Industria Comercio y Trabajo, Comunicaciones y Obras Públicas, Departamento de Salubri-

${ }^{4}$ Archivo General de la Nación (en adelante AGN), Fondo Obregón/Calles, 121-G-S-2. 
dad, así como por comisionados del Gobierno del Distrito, del Ayuntamiento de la ciudad de México, y por un periodista y un abogado consultor. ${ }^{5}$ Todos estos comisionados tendrían el cargo honorífico de Agentes Especiales Sanitarios, contarían con las atribuciones y facultades que marcaba el Código Sanitario en vigor, pero sus acuerdos y resoluciones se tomarían por mayoría de votos, y el personal administrativo que requirieran se integraría por comisiones de las secretarías de estado, del gobierno del Distrito y del ayuntamiento de la ciudad de México.

Tan pronto fue creada, la Comisión Ejecutiva Sanitaria del Distrito Federal comenzó a dar resultados, pues diecisiete días después de instalada rindió un informe de sus labores en el que destacó que había

logrado un éxito de la más grande trascendencia: hacer que autoridades que se hallaban en abierta pugna, como el ayuntamiento de la ciudad de México y el Departamento de Salubridad Pública y el Gobierno del Distrito, caminen en perfecta armonía, auxiliándose entre sí para la realización de la obra de saneamiento del Distrito Federal. Sin la unión

${ }^{5}$ Los nombres de todos estos comisionados fueron: Heberto Alcázar, Manuel Carpio, Ing. Miguel Ajuria, Ing. Carlos F. de Landero, Dr. Jesús E. Monjaraz, Francisco Rodríguez del Campo, Luis F. Seoane, Rómulo Velasco Ceballos, y Lic. Ramón de la Barrera. Vid. AGN, Fondo Obregón/Calles, 121-G-S-2. de estas tres autoridades habría sido seguramente imposible avanzar nada en punto de tanto interés como el del saneamiento. ${ }^{6}$

Gracias a la colaboración entre las distintas autoridades integrantes de la Comisión Ejecutiva, se llevaron a cabo diversas acciones en beneficio de la salubridad de la población del Distrito. Así, por ejemplo, se elaboraron y enviaron varias propuestas al ayuntamiento de México, para que el gobierno municipal empleara los métodos más apropiados para la recolección, extracción y eliminación de basuras, pues por esos días dicha corporación estaba por firmar un contrato para trasladar las basuras de la ciudad a cuatro tiraderos ubicados en los cuatro puntos cardinales de la ciudad en las cercanías de los suburbios.

Asimismo, la comisión reportó que, a instancias suyas, el ayuntamiento de México y el gobierno del D.F. tomaron medidas para que los propietarios de lotes llenos de basura los limpiaran, para que se asearan las calles, para reubicar a los vendedores ambulantes establecidos en el centro de la ciudad, para que estudiantes de medicina realizaran trabajos de concientización entre la población sobre cuestiones de higiene, para la instalación de baños en las escuelas primarias, para obras de saneamiento en la

${ }^{6}$ Ibidem . 
NOTAS

colonia la Bolsa, para la organización de eventos públicos destinados a recabar fondos para las obras de higiene y para la construcción de un mercado en la municipalidad de Tacuba. $^{7}$

Sin embargo, la concordia entre autoridades duró muy pocos días. La comisión emprendió con tal ánimo sus funciones que no tardó en tener conflictos con otras dependencias, e incluso llegó a cuestionar algunas de las decisiones del Presidente de la República. Por ejemplo, luego de calificar de "lamentablemente ineficiente" la labor realizada por el Departamento de Salubridad Pública, el 17 de agosto de 1922, conminó al Presidente a derogar las reformas y adiciones a la Ley de Hacienda del Distrito Federal decretadas por él mismo el 17 de julio, las cuales disponían que los espacios libres de la ciudad (patios y jardines), que excedieran en más de 100 metros a la extensión de la parte construida de una propiedad, quedarían gravados por una contribución predial más alta.

Si para el gobierno esta medida resultaba necesaria para aliviar la escasez de recursos que le afectaba en ese momento, para la Comisión dicha disposición tendería a disminuir los espacios libres de la ciudad y esto a su vez agravaría las condiciones higiénicas de la misma, pues, ocupando

${ }^{7}$ Ibidem. apenas un $3 \%$ de la superficie construi$\mathrm{da}$, los espacios libres (jardines y patios) de la ciudad tenderían a disminuir de continuar en vigor la disposición de gravarlos con un impuesto predial más elevado que el de las propias fincas urbanas. El Ejecutivo pareció comprender este razonamiento, pues accedió a revocar el decreto el 12 de septiembre. ${ }^{8}$

Es posible suponer que el origen de los conflictos que tuvo la Comisión con otras autoridades que atendían los servicios sanitarios de la ciudad radicaba en el hecho de que sus decisiones contaban con el respaldo del Ejecutivo Federal, lo cual en la práctica significó que las funciones de las otras dependencias del gobierno federal, establecidas constitucionalmente, eran desplazadas por el poder ejecutivo, quien a su vez tomaba decisiones apoyado en los informes de la Comisión creada por él mismo. Al menos éste fue el mecanismo que enmarcó el funcionamiento de la Comisión durante los dos primeros meses de su creación. Y fue precisamente esta situación la que salió a flote cuando se discutió el proyecto legal de creación de la Comisión, mismo que se encargó de elaborar la Comisión y de enviarlo para su dictamen a las autoridades sanitarias.

La amenaza que significaba, ya no para los servicios sanitarios de la

${ }^{8}$ Ibidem. 
ciudad, sino para la jurisdicción de las autoridades sanitarias establecidas, el adoptar el funcionamiento de una comisión ejecutiva que estaba por encima de éstas, fue denunciada por el jefe del Departamento de Salubridad Pública en un oficio dirigido al Presidente Álvaro Obregón, en el que le manifestó su profundo desacuerdo con el proyecto para el establecimiento legal de dicha comisión, mismo que los integrantes de la misma le habían hecho llegar días antes. El punto en desacuerdo era que por las amplias facultades que se otorgaban a la Comisión en dicho proyecto, ésta en realidad vendría a sustituir a las autoridades ya constituidas, cosa con la que el Ejecutivo había dicho no estar de acuerdo, además de no haber fundamentos legales que legitimaran su creación. ${ }^{9}$ Por estas razones, el jefe del Departamento de Salubridad Pública envió al Presidente un dictamen sobre dicho proyecto para que los abogados de la presidencia lo estudiaran y dictaminaran.

${ }^{9}$ En el citado proyecto se facultaba a la Comisión Ejecutiva Sanitaria para aplicar en el Distrito Federal las leyes sanitarias, y vigilar y exigir su cumplimiento en todo lo relativo a la salubridad local. Asimismo, se ampliaba el número de integrantes de la misma con la incorporación de comisionados de la Procuraduría General de la República, del Consejo Superior de Salubridad y de los Ayuntamientos Foráneos, y se hacía depender a la comisión del Ejecutivo por conducto de la Secretaría de Gobernación. Vid. AGN, Fondo Obregón/ Calles, 121-G-S-2.
En este dictamen, emitido el 7 de agosto de 1922, los abogados del Departamento de Salubridad advirtieron al Presidente que legalmente la Secretaría de Gobernación ya no tenía a su cargo el servicio sanitario local del Distrito Federal y Territorios, como se pretendía en el proyecto, sino que esta facultad correspondía directamente al Departamento de Salubridad Pública, pues tal había sido la idea de los constituyentes. Si se insistía en crear la Comisión como dependencia del Ejecutivo, entonces debía reformarse la fracción XVI del artículo 73 constitucional y la Ley de Organización de Secretarías, del 25 de diciembre de 1917, facultad que no tenía el Presidente conforme al Código Sanitario del 30 de diciembre de $1902 .{ }^{10}$

Por ahora no sabemos si el Presidente se convenció de la necesidad de descentralizar la atención de los servicios sanitarios de la capital, dejando en manos del Departamento de Salubridad Pública esta tarea, o si consideró difícil en ese momento obtener del Congreso la aprobación a la enmienda constitucional que le hubiese dado el control sobre los mismos. Lo cierto es que el 7 de septiembre de 1922 expidió un nuevo acuerdo en cuyos considerandos reconoció la inconstitucionalidad de otorgar a la Comisión Ejecutiva funciones sanitarias, así como los constantes conflictos que

${ }^{10}$ Ibidem . 
NOTAS

surgían entre ésta y las demás autoridades sanitarias. En atención a estas razones, decretó la conversión de la Comisión Ejecutiva en una Comisión Auxiliar de Salubridad del Distrito Federal, cuyas funciones e iniciativas sanitarias quedarían subordinadas al Departamento de Salubridad Pública y al Consejo Superior de Salubridad. ${ }^{11}$

No obstante haber sido disminuido el alcance de sus iniciativas para mejorar las condiciones sanitarias del Distrito, casi de inmediato la nueva comisión auxiliar llevó a cabo un diagnóstico sobre las condiciones sanitarias imperantes en todas las colonias de la ciudad de México y en otras poblaciones del Distrito, y propuso un conjunto de proyectos para resolver su problemática sanitaria. Lamentablemente dichos informes están perdidos. ${ }^{12}$

Paralelamente a la creación de la Comisión Auxiliar, desde marzo de 1922 y hasta marzo del siguiente año, se llevaron a cabo reuniones entre comisionados del Ejecutivo Federal y del Ayuntamiento de México con el objeto de deslindar la competencia entre las entidades de gobierno del Distrito y el ayuntamiento, pues los

${ }^{11}$ Ibidem.

${ }^{12}$ En el AGN, Fondo Obregón/Calles, varios expedientes dan noticia de estos proyectos e informes, más no los incluyen. Véanse expedientes 121-C-S-5 y 121-C-C-13. conflictos de jurisdicción entre ambas habían llegado a un punto muy crítico. Conforme avanzaron los trabajos de estas reuniones se incorporó a ellas un comisionado del Departamento de Salubridad Pública, toda vez que se abordó en ellas la cuestión de la competencia jurisdiccional del gobierno federal y municipal en los asuntos de salubridad pública. ${ }^{13}$

La iniciativa del gobierno federal de esclarecer en estas reuniones las facultades que correspondían a las diversas instancias de gobierno del Distrito no tenía precedentes. Tal vez por eso las autoridades municipales de la ciudad de México, por medio de su presidente municipal, Jorge Prieto Laurens, y de los ayuntamientos foráneos, solicitaron al Presidente Obregón, el 23 de enero de 1923, debatir y resolver otras cuestiones igualmente importantes para el gobierno de la capital, como lo era el de las funciones de la Justicia de Paz.

En otro momento, el 9 de febrero, el ayuntamiento de Tacuba pidió también al Presidente que se incluyera en esas reuniones una representación de cada uno de los ayuntamientos foráneos del Distrito, porque la inva-

${ }^{13}$ El 16 de marzo de 1922, el gobernador del Distrito designó a René Lajous y Octavio Medellín Ostos como representantes del Ejecutivo en esas reuniones. Para el 23 de enero de 1923, se incorporó a éstas un comisionado del Departamento de Salubridad Pública. Vid. AGN, Fondo Obregón/Calles, 242-M1-D. 
sión de facultades de otras dependencias de gobierno en sus funciones afectaba mayormente a éstos. El presidente, sin embargo, consideró que no era necesaria la intervención de todos los ayuntamientos porque lo que se discutía eran cuestiones de "mero detalle" y porque al quedar definidos esos detalles con el ayuntamiento de la ciudad de México se seguiría el mismo criterio en los demás municipios. $^{14}$

No obstante el trabajo de negociación entre el gobierno federal y el municipal para dirimir sus jurisdicciones de gobierno, los conflictos entre ambos siguieron produciéndose. Esta vez, el 9 de febrero de 1923, el ayuntamiento de México exigió al Ejecutivo que, a reserva de los acuerdos a los que pudiera llegarse, ordenara inmediatamente al gobernador del Distrito se abstuviera de intervenir en las funciones municipales relativas al cobro de contribuciones en el mercado de la Lagunilla y a la expedición de licencias que dicho funcionario había decretado suspender. ${ }^{15}$

Apremiados por los conflictos, los integrantes de la comisión negociadora presentaron al Presidente el 6 de marzo sus acuerdos para que éste los sancionara y resolviera, como en efecto lo hizo. Dichos acuerdos colo-

${ }^{14}$ AGN, Obregón/Calles, 242-M1-D.

${ }^{15}$ El 29 de enero, el Presidente comunicó al ayuntamiento de México que su queja ya era atendida por el gobernador del Distrito. Vid. AGN, Obregón/ Calles, 242-M1-D. caban al Ejecutivo Federal, por conducto del Departamento de Salubridad Pública, como la máxima autoridad sanitaria tanto en la República como en el D.F., por lo cual el gobierno del Distrito y el ayuntamiento de México quedaban obligados a obedecer sus disposiciones. No obstante, se reconoció que el Consejo Superior de Salubridad conservaría las funciones que le confería el Código Sanitario en la ciudad de México, que el ayuntamiento de la misma podría enviar a dicho consejo un representante con derecho de voz, y que, en su carácter de auxiliar y delegado de la suprema autoridad sanitaria, continuaría aplicando las disposiciones de salubridad conforme a las disposiciones administrativas vigentes. Asimismo, se acordó que en materia municipal la Inspección General de Policía obedecería las órdenes directas del Ayuntamiento, para lo cual el gobierno del Distrito debería dar las órdenes que estimara prudentes. En materia de la eficacia de los servicios municipales, se acordó que el ayuntamiento tendría inspectores especiales de reglamentos y que, junto con el gobierno del Distrito, se haría una revisión completa de los bandos y reglamentos de policía y buen gobierno con el fin de deslindar cuáles eran las facultades de una y otra instancia de gobierno. ${ }^{16}$

${ }^{16}$ Ibidem . 
NOTAS

Hubo, sin embargo, puntos de acuerdo provisional entre el Departamento de Salubridad y el ayuntamiento que el Presidente no aprobó, quizá porque suponían no tanto la pérdida de facultades como de recursos para el gobierno federal. Uno de estos acuerdos señalaba que el ayuntamiento de México retendría para sí, por tratarse de arbitrios municipales, todos los recursos que por concepto de derechos y multas producían los servicios sanitarios de la ciudad, mismos que en ese momento ingresaban a la tesorería federal. El Presidente rechazó tal propuesta

por considerar que debería ser la hacienda federal la que percibiera las cantidades que por concepto de derechos y multas en materia de sanidad o sanitaria general hubieran de recaudarse, en virtud de la acción del Consejo Superior de Salubridad en la ciudad de México, de acuerdo con las disposiciones legales vigentes. ${ }^{17}$

Otro acuerdo que rechazó el Presidente proponía que el inspector general de policía fuera nombrado mediante el voto del gobernador y del ayuntamiento, y que el Presidente ratificara su elección.

Como puede observarse, el gobierno de Álvaro Obregón tuvo que enfrentarse a los problemas del Distrito Federal que administraciones

\footnotetext{
${ }^{17}$ Ibidem.
}

pasadas no habían podido resolver: la insuficiencia de los servicios públicos y los conflictos políticos entre el gobierno federal y los ayuntamientos, así como también los que surgieron entre las instancias del gobierno federal involucradas en la atención de dichos servicios. El trasfondo de estos conflictos fue, por un lado, una creciente e insatisfecha demanda social por la mejora de los servicios públicos, que tenía como vértice la ineficacia de las administraciones municipales; por otro, la falta de una estructura legal que determinara claramente las funciones y atribuciones de los distintos niveles de gobierno; $y$, finalmente, la disputa por el poder político alojada en los ayuntamientos del Distrito. A todo esto, la insuficiencia de recursos tanto del gobierno federal, como de los gobiernos municipales, contribuyó poderosamente a acentuar la naturaleza caudillesca y centralizadora del nuevo Estado.

A juzgar por la materia de los acuerdos aprobados por el Presidente, todos los cuales debían traducirse en reglamentos, puede decirse que las cuestiones de mayor conflicto entre las autoridades federales y las municipales en el Distrito Federal, durante el gobierno de Álvaro Obregón, fueron las relativas a la salubridad pública, al apoyo de la policía en materia de administración municipal, a la expedición y aplicación de 
reglamentos para los servicios urbanos, y al destino de los ingresos producidos por éstos. Habría que indagar sobre los resultados de la aplicación de los acuerdos a que llegaron las respectivas autoridades de la ciudad y del gobierno federal para conocer si sus continuos conflictos tendieron a desaparecer. Sin embargo, si consideramos que años después de haber sido tomados estos acuerdos, el mismo Álvaro Obregón introdujo la iniciativa de suprimir los ayuntamientos argumentando la ineficacia administrativa de los mismos, su proclividad al libertinaje político y su extrema dependencia de los fondos de la nación, podríamos concluir que los esfuerzos de su gobierno por eliminar las fuentes de conflicto con las autoridades municipales fracasaron. La razón de su fracaso estribó, quizás, en que no pudo contener la lucha política que diversos grupos libraban contra su gobierno desde los ayuntamientos, pero también en que desde un principio negó a los ayuntamientos una autonomía real para el ejercicio de sus funciones administrativas. Como quiera que haya sido, su intento por resolver los problemas de jurisdicción entre autoridades nos habla de esa lógica política surgida de la revolución, por la cual el Estado buscó ganarse el apoyo de grupos de la sociedad organizada mediante la atención a sus demandas. Los ayuntamientos, con todo y ser una institución social y no una organización civil, gracias al reconocimiento del municipio libre en la Constitución, se colocaron frente al gobierno como una institución fortalecida políticamente que exigió solución a las demandas sociales. Al reconocer el carácter representativo de los ayuntamientos y buscar resolver sus problemas de jurisdicción, el gobierno buscó en la misma medida atender las demandas de la sociedad. Sin embargo, las soluciones que planteó a estas demandas no salieron del marco centralizador desde el cual el gobierno federal buscó siempre resolver los problemas políticos, técnicos, y financieros del Distrito Federal. Por ello, puede decirse que los primeros gobiernos de la Revolución practicaron viejas soluciones a los viejos problemas de la capital, los cuales, como hemos visto hasta aquí, eran los de su autonomía político-administrativa y los del funcionamiento de los servicios públicos. 
CITAM Derechos Reservados.

La reproducción total o parcial de este artículo se podrá hacer si el ITAM otorga la autorización previamente por escrito. 